\title{
ESTUDO DA FOTODEGRADAÇÃO DE EFLUENTE DE INDÚSTRIA DE CELULOSE E PAPEL EMPREGANDO OS FOTOCATALISADORES DE $\mathrm{TiO}_{2}, \mathrm{ZnO} \mathrm{E} \mathrm{Nb}_{2} \mathrm{O}_{5}$
}

Rubiane Ganascim Marques

Veronice Slusarki Santana

\section{Nádia Regina Camargo Fernandes-Machado}

RESUMO:O setor de celulose e papel apresenta um efluente com uma elevada carga orgânica e alta coloração. Os tratamentos convencionais são eficientes para redução de DQO e DBO do efluente, mas mesmo após tratamento biológico, o efluente apresenta uma elevada coloração. Muitas indústrias já estão utilizando técnicas de tratamento terciário de efluentes para o polimento do mesmo, como a ultrafiltração. Uma alternativa para o polimento é a fotocatálise heterogênea. $O$ presente trabalho teve como objetivo o estudo da degradação fotocatalítica de efluente de uma indústria integrada de produção de celulose e papel. Foram realizadas as caracterizações dos catalisadores através de difração de raio-x e análise textural. Os testes fotocatalíticos foram realizados em reator batelada sob irradiação UV $(250 \mathrm{~W})$. Os catalisadores reduziram parcialmente a carga orgânica do efluente. Os melhores resultados foram obtidos com $\mathrm{ZnO}$, sendo alcançada uma redução de $35 \%$ da $\mathrm{DQO}$ quando foi utilizado $\mathrm{ZnO}$ mássico calcinado a $500^{\circ} \mathrm{C}$.

Palavras chaves: Fotocatálise heterogênea. Efluente Kraft. Pentóxido de nióbio. 


\section{INTRODUÇÃO}

A indústria de celulose e papel é uma das indústrias mais importantes no mundo (Koet al., 2009). O setor brasileiro de produção de celulose e papel vem contribuindo de forma significativa para o desenvolvimento sócio-econômico do país. No Brasil existem 222 empresas ligadas diretamente à indústria de celulose e papel com atividades em 539 municípios localizados em 18 estados (Bracelpa, 2012).

Em 2009, a produção mundial de papel e polpas de madeira foi estimada em 177 milhões de toneladas de celulose e 370 milhões de toneladas de papel (Bracelpa, 2012). Neste contexto, o Brasil é o $4^{\circ}$ maior produtor de celulose (14 milhões de toneladas produzidas em 2010) e o 9ำ maior produtor de papel (9,8 milhões de toneladas produzidas em 2010) no mundo.

Segundo Andrade (2006), com o crescente aumento da produção de celulose e papel, as empresas buscam melhorar os processos industriais empregados, pois estes devem se basear na utilização de informações seguras, precisas e diretamente relacionadas ao produto final para continuarem sendo competitivas no mercado. Em praticamente todas as etapas de produção de celulose e papel ocorre geração de algum tipo de poluente (Pokhrel e Viraraghavan, 2004).

A carga poluidora, contida nos despejos procedentes dos processos de produção de celulose e papel, varia de fábrica para fábrica, dependendo do tipo de polpação, a qualidade da matéria prima empregada e do produto final desejado (SENAI, 1995).

O processo de polpação predominante no mundo é a polpação kraft (PeraltaZamoraet al., 1997, Cardoso, 2006), uma das características desse processo é a geração de um efluente com alta DQO, alta demanda química de oxigênio (DBO), elevada coloração, turbidez e baixa concentração de oxigênio dissolvido.

A seguir são apresentados resumidamente as principais fontes de geração de efluente em uma planta integrada de celulose e papel.

No preparo da madeira, cascas de madeira, areia, solo e sujeira são removidos, utilizando-se água para a lavagem das toras. Os despejos líquidos gerados nesta etapa apresentam baixa coloração, valores de pH em torno de sete,e alta concentração de sólidos suspensos e sólidos dissolvidos . (IPT,1988). 
Na etapa de cozimento, o efluente gerado é chamado de licor negro, este efluente contém compostos de lignina e seus derivados, extrativos, resinas álcoois, fenóis, acetona, etc. isso acarreta em uma elevada DBO, DQO, AOX e compostos orgânicos voláteis (Pokhrel e Viraraghavan, 2004).

Na lavagem da polpa é retirado o residual do licor negro contido na mesma, e este efluente apresenta os mesmos compostos químicos do efluente retirado do digestor (Pokhrel e Viraraghavan, 2004). O efluente que sai do digestor e da lavagem da polpa geralmente entra no ciclo de recuperação química, e não vai para o tratamento de efluentes (Cardoso, 2006).

O branqueamento é uma das etapas da fabricação da celulose e papel mais poluidora (com maior carga de DQO), pois é nesta fase que as ligninas ainda presentes, os fenóis, as resinas ácidas e outros reagem com o cloro formando os compostos altamente tóxicos como os AOX (Catalkaya e Kargi, 2008; Pokhrel e Viraraghavan, 2004). Foram identificados mais de 300 compostos orgânicos em efluentes de branqueamento, alguns de reconhecido efeito tóxico e/ou genotóxico (Peralta-Zamoraet al.; 1997).

Já o preparo do papel na máquina é a etapa gera mais quantidade de efluentes na fábrica, este efluente apresenta um alto teor de fibras e aditivos que são adicionados à massa do papel (Ali e Sreekrishnan, 2001) e contêm compostos orgânicos, corantes inorgânicos, fibras, acetona, etc (Pokhrel e Viraraghavan, 2004).

Antes de seguir para a ETE (Estação de Tratamento de Esgoto) os efluentes gerados nos diferentes processos são misturados, resultando em um efluente com alta DQO, DBO, turbidez, cor e baixo oxigênio dissolvido.Os efluentes oriundos das indústrias do setor de celulose e papel geralmente apresentam elevada cor e turbidez residual, por isso estas indústrias buscam minimizar cada vez mais a carga de DQO e DBO, assim como a cor de seu efluente. Diversas técnicas têm sido aplicadas, algumas com baixa eficiência e outras com alta eficiência, mas com um alto custo. Dentre as técnicas sofisticadas e caras, destaca-se a ultrafiltração.

Uma alternativa a este tipo de tratamento seria a fotocatálise heterogênea. A fotocatálise heterogênea é uma alternativa promissora para a remoção de poluentes orgânicos em água, podendo ser aplicada também para o polimento dos efluentes.

Segundo Lasaet al. (2005) três componentes devem estar presentes para que ocorra a reação fotocatalítica heterogênea: a emissão de um fóton (com comprimento de 
onda adequado ao catalisador), uma superfície catalítica (geralmente um semicondutor) e um material fortemente oxidante (usualmente o oxigênio).

O processo fotocatalítico é iniciado com a emissão de um fóton com a energia igual ou superior à energia para promover um elétron da banda de valência para a banda de condução que o fotocatalisador necessita em sua superfície, resultando em uma excitação molecular (energia de "band gap"). Essa energia tem ordem de grandeza de poucos elétrons volts.

Essa excitação molecular leva a uma geração de elétrons se movimentando da banda de valência para a banda de condução, criando assim uma lacuna eletrônica positiva na banda de valência, esse processo pode ser representado na equação 1.

Fotocalisador + fóton $\rightarrow \mathrm{e}^{-}+\mathrm{h}^{+}$

A formação do par lacuna-elétron está representada na Figura 1.

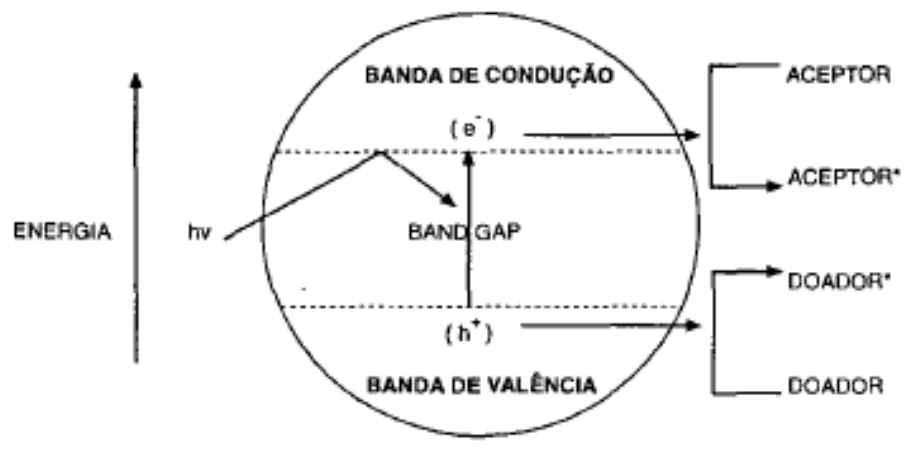

Figura 1. Princípios eletrônicos de um processo fotoquímico (Fonte: PERALTAZAMORA et al. 1997).

A reação fotocatalítica procede por uma série de etapas reacionais (LASA et al., 2005). Primeiramente ocorre a foto-excitação do catalisador, gerando a formação do par elétron-lacuna (equação 1).

A segunda etapa pode ocorrer de três maneiras diferentes, pode ocorrer uma transferência eletrônica no substrato adsorvido $\left(R X_{a d s}\right)$ (equação 2$)$, na água adsorvida (equação 3) ou no íon $\mathrm{OH}$ - adsorvido (equação 2.4) no catalisador com a lacuna gerada. 


$$
\begin{array}{lc}
\mathrm{h}^{+}+\mathrm{RX}_{\mathrm{ads}} \rightarrow \mathrm{RX}^{+}{ }_{\mathrm{ad}} & 2 \\
\mathrm{~h}^{+}+\mathrm{H}_{2} \mathrm{O}_{\mathrm{ads}} \rightarrow \cdot \mathrm{OH}_{\mathrm{ads}}+\mathrm{H}^{+} & 3 \\
\mathrm{~h}^{+}+\mathrm{OH}_{\mathrm{ads}}^{-} \rightarrow \cdot \mathrm{OH}_{\mathrm{ads}} & 4
\end{array}
$$

A terceira etapa é de grande importância, devido à geração de altas concentrações de $\mathrm{OH}^{-}$,pela dissociação da água em íons.

$$
\mathrm{H}_{2} \mathrm{O} \rightarrow \mathrm{OH}_{\text {ads }}^{-}+\mathrm{H}^{+}
$$

Oxigênio molecular atua como aceptor de elétrons na reação de transferência eletrônica.

$\mathrm{e}^{-}+\mathrm{O}_{2} \rightarrow \mathrm{O}_{2}^{-}$

Anions superóxidos podem ser envolvidos subsequentemente em reações em série:

$$
\begin{aligned}
& \mathrm{O}_{2}{ }^{-}+\mathrm{H}^{+} \rightarrow \mathrm{HO}_{2}{ }^{-} \\
& \mathrm{H}^{+}+\mathrm{O}_{2}{ }^{-}+\mathrm{HO}_{2}{ }^{-} \rightarrow \mathrm{H}_{2} \mathrm{O}_{2}+\mathrm{O}_{2}
\end{aligned}
$$

E a foto-conversão do peróxido de hidrogênio produz radicais hidroxilas.

$$
\mathrm{H}_{2} \mathrm{O}_{2}+\mathrm{hv} \rightarrow 2 \cdot \mathrm{OH}
$$

Finalmente, os radicais hidroxilas oxidam os poluentes orgânicos adsorvidos na superfície do catalisador.

$$
\cdot \mathrm{OH}_{\mathrm{ads}}+\mathrm{RX} \text { ads } \rightarrow \text { intermediário }
$$

Os radicais $\cdot \mathrm{OH}$ produzidos são altamente reativos e atacam as moléculas do poluente levando à mineralização do mesmo. 
Existem duas possíveis explicações para a reação fotocatalítica. Segundo Lasa et al. (2005) muitos autores sugerem uma oxidação indireta via radical hidroxila adsorvido na superfície do catalisador (reação 4 e 10) e outros autores argumentam em favor da oxidação direta do poluente via lacuna formada na excitação do catalisador (equação 2).

O presente trabalho tem como objetivo estudar a fotodegradação de efluente de após o tratamento secundário de uma indústria de celulose e papel com processo integrado.

\section{MATERIAIS E MÉTODOS}

Como catalisadores foram utilizados dióxido de titânio comercial (Kronos), óxido de zinco (Biotec) e pentóxido de nióbio (CBMM). Os óxidos passaram por um processo de ativação para sua utilização como fotocatalisador. Os catalisadores foram lavados com água deionizada para a retirada de impurezas, e em seguida os materiais foram filtrados à vácuo e seco em estufa a $100^{\circ} \mathrm{C}$ por $24 \mathrm{~h}$.

Após a limpeza dos catalisadores, os mesmos foram peletizados sob pressão de $3,0 \times 10^{3} \mathrm{kgf} / \mathrm{cm}^{2}$, triturados e peneirados $(0,150$ e $0,300 \mathrm{~mm})$. Os catalisadores então foram calcinados a $500^{\circ}$ Cpor 5 horase armazenados.

O catalisador P25 Aeroxide® P25 Evonik (DEGUSSA) foi utilizado comparativamente na sua forma comercial, já que o mesmo tem conhecida atividade catalítica.

Os catalisadores foram caracterizados através de análise textural e difratometria de raio-X. A caracterização de análise textural foi realizada utilizando o equipamento Quanta Chrome NOVA® 1200e (DEQ/UEM), a partir das isotermas de equilíbrio de adsorção física de $\mathrm{N}_{2}$.

As análises de raio- $X$ foram realizadas em Difratômetro de Raios-X Bruker D8 Advance com fonte de $\mathrm{Cu}$, tensão de $40 \mathrm{kV}$, corrente de $30 \mathrm{~mA}$ e filtro de níquel. Os picos obtidos foram comparados com o banco de dados publicados por JCPDS (1995).

O efluente foi cedido pela indústria Klabin S/A unidade Monte Alegre. A coleta do efluente ocorreu após o tratamento secundário de lodo ativado, sendo utilizado até $24 \mathrm{~h}$ após a coleta. 
A unidade reacional consistiu em um béquer de vidro de $1000 \mathrm{~mL}$, com sistema de agitação magnética, com lâmpada de 250 W da General Eletric (GE) emitindo luz ultravioleta, localizada a15cm da superfície do efluente.

A atividade fotocatalítica do catalisador foi avaliada através da reação de fotodegradação do efluente industrial.

Os testes fotocatalíticos foram realizados na unidade reacional em batelada, por $6 \mathrm{~h}$, à temperatura ambiente, com uma concentração de catalisador de $1 \mathrm{~g} / \mathrm{L}$, contendo $500 \mathrm{~mL}$ de efluente, sob agitação magnética e irradiação de luz, sem aeração. Uma alíquota de $5 \mathrm{~mL}$ foi retirada a cada hora e filtrada em filtro Millipore $0,45 \mu \mathrm{me}$ armazenada em congelador.

No teste de fotólise foram utilizadas as mesmas condições do teste fotocatalítico, mas com ausência do catalisador.

O acompanhamento da degradação fotocatalítica do efluente foi realizado através da redução DQO e compostos de cloro-ligninas (metodologia utilizada por Wang et al, 1992).

\section{RESULTADOS E DISCUSSÕES}

\subsection{ANÁLISE TEXTURAL}

A figura 2 apresenta uma isoterma adsorção/dessorção para o $\mathrm{TiO}_{2} \mathrm{Kronos}$. Podese observar que a isoterma apresentou formato próximo à do tipo IV, com histerese o que caracteriza sólidos mesoporosos. As histereses do tipo $\mathrm{H} 2$ correspondem a uma distribuição de tamanho de poros e forma definida; associado também a poros tipo tinteiro.O $\mathrm{TiO}_{2}$ (Kronos) apresentou uma área superficial de 9,6 m²/g. 


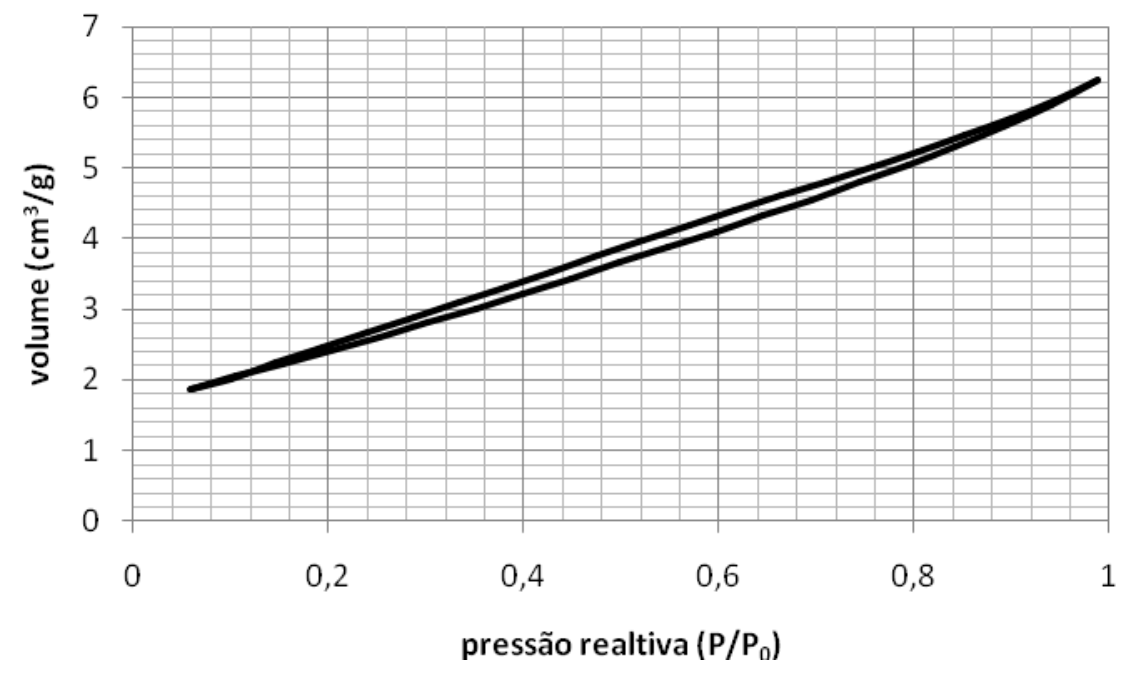

Figura 2- Isoterma do catalisador $\mathrm{TiO}_{2}$ calcinado a $500^{\circ} \mathrm{C}$.

A figura 3 apresenta a isoterma adsorção/dessorção para o $\mathrm{TiO}_{2}$ Aeroxide® P25. Pode-se observar que a isoterma apresentou-se semelhante à obtida do dióxido de titânio Kronos (Figura 2), com isoterma tipo IV e histerese tipo H2. O que pode ser observado é que o P25 mostrou-se mais poroso que o dióxido de titânio Kronos. Sua área específica total foi de $69,5 \mathrm{~m}^{2} / \mathrm{g}$.

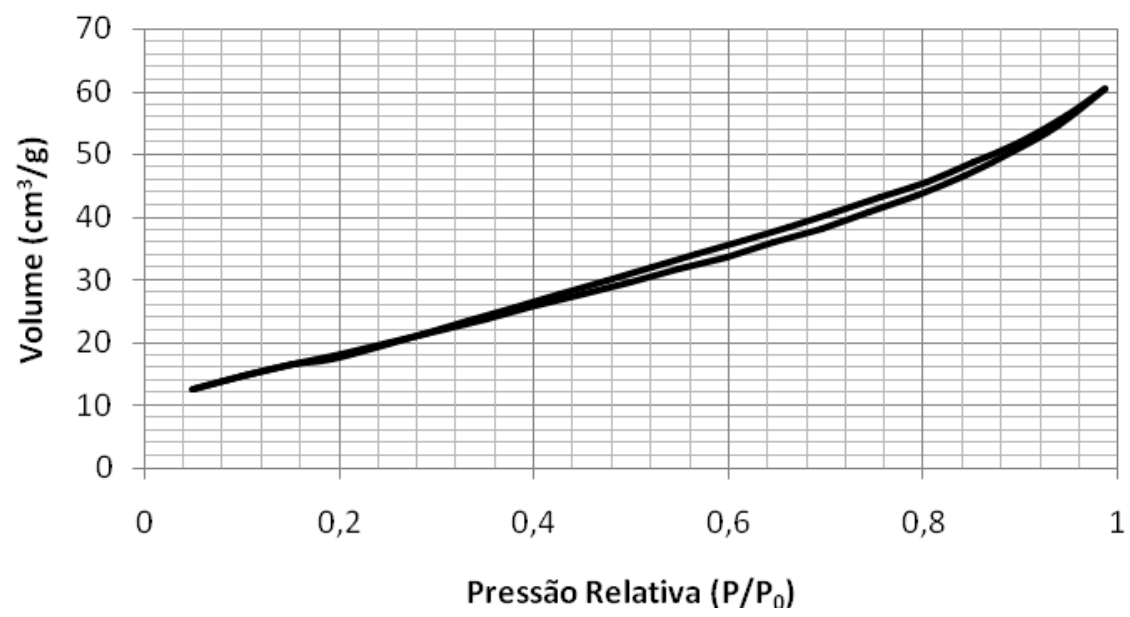

Figura 3 - Isoterma do catalisador $\mathrm{TiO}_{2}$ Aeroxide ${ }^{\circledR}$ P25.

Observa-se na Figura 4 que o pentóxido de nióbio apresenta uma isoterma característica do tipo IV com uma grande histerese que evidencia a mesoporosidade 
do catalisador. A área superficial calculada pelo método BET foi de $79,5 \mathrm{~m}^{2} / \mathrm{g}$.

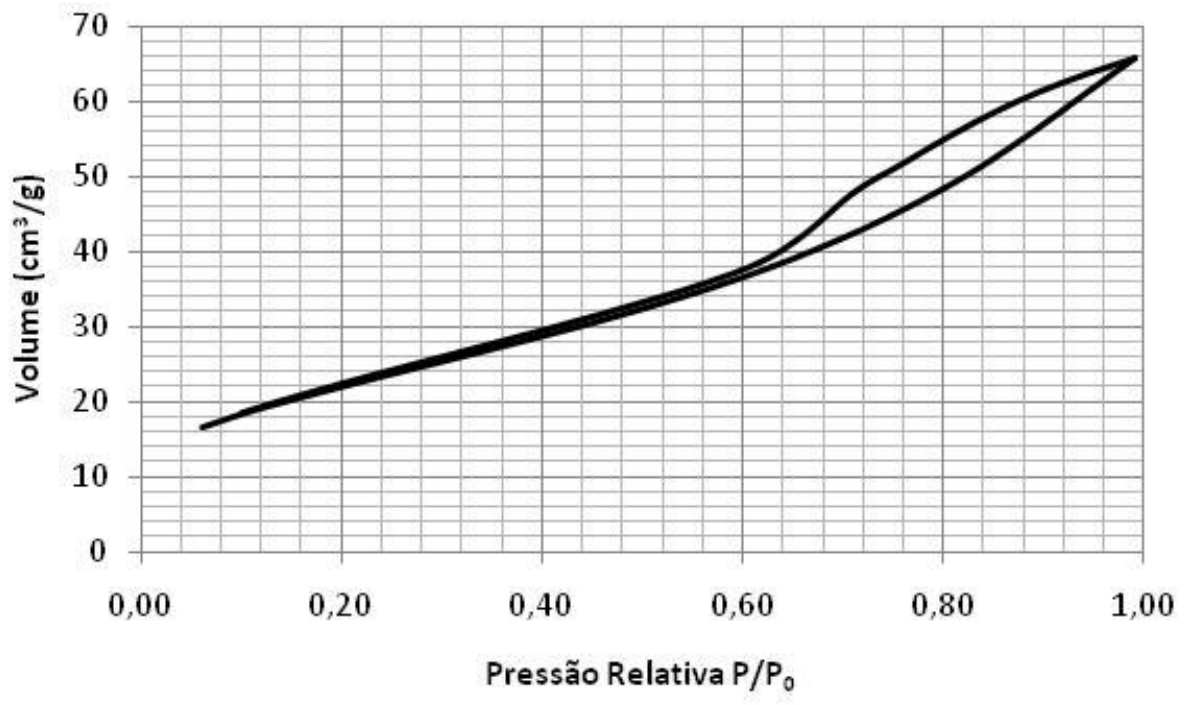

Figura 4 - Isoterma do catalisador $\mathrm{Nb}_{2} \mathrm{O}_{5}$.

$\mathrm{Na}$ figura 5 observa-se a isoterma obtida para o óxido de zinco, onde esta foi muito semelhante a isoterma obtida pelo dióxido de titânio Kronos sendo do tipo IV, com uma área superficial de $6,0 \mathrm{~m}^{2} / \mathrm{g}$.

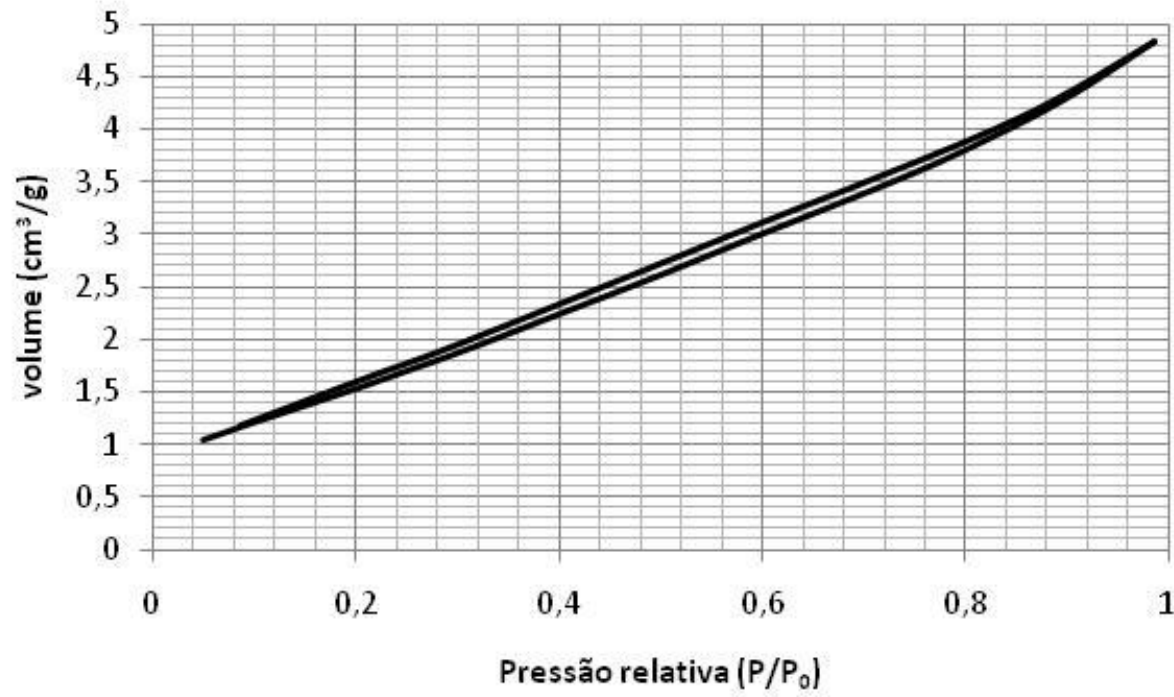

Figura 5 - Isoterma do catalisador $\mathrm{ZnO}$.

\subsection{DIFRAÇÃO DE RAIO-X (DRX)}


Para aidentificação das fases cristalinas dos óxidos semicondutores foiutilizado o banco de dados JCPDS, encontrado no programa PCPDFWIN.

Observa-se na Figura 6 os difratogramas obtidos para o dióxido de titânio Kronos e P25. Ambos estão na forma tetragonal. Para $\circ \mathrm{TiO}_{2} \mathrm{Kronos}$ verifica-se a presença da $100 \%$ da fase anatase que é caracterizada pelo pico de maior intensidade no ângulo $2 \theta=25,3$. Já no difratograma do Aeroxide ${ }^{\circledR}$ verifica a presença da fase anatase e da fase rutilo (caracterizada pela maior intensidade do pico em $2 \theta=27,9$ ), na proporção de $12 \%$ rutilo e $88 \%$ de anatase.
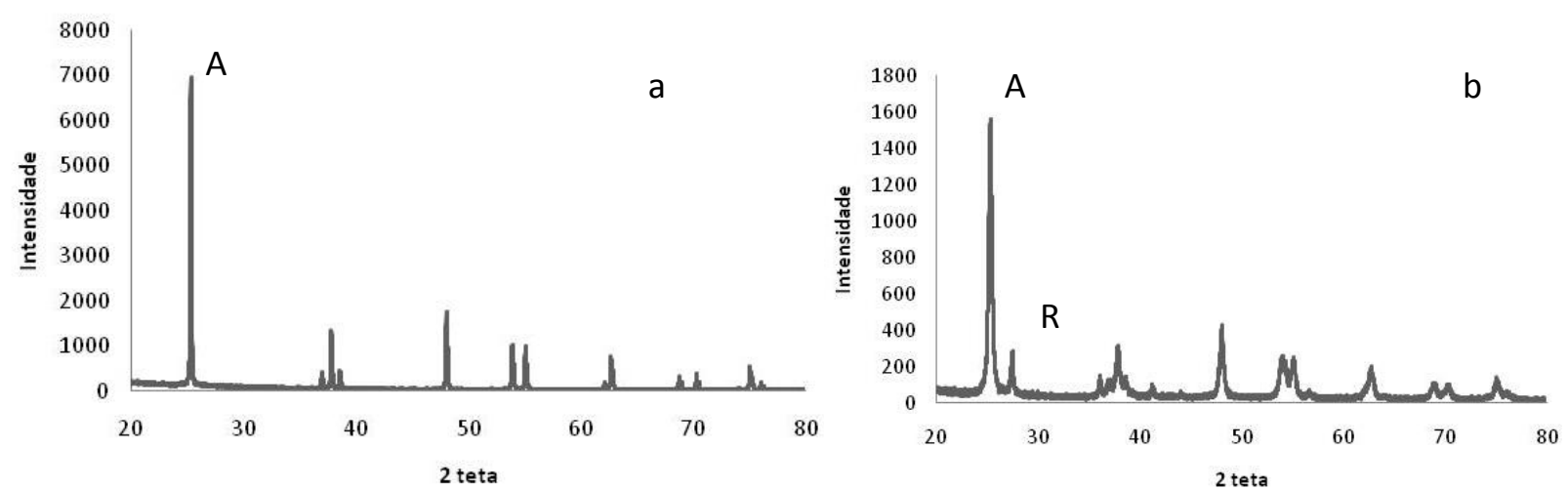

Figura 6 - Difratograma de raio-X do $\mathrm{TiO}_{2}$ Kronos (a) e TiO2 Aeroxide® P25 (b).

Na Figura 7 é apresentado o difratograma do pentóxido de nióbio e óxido de zinco.O $\mathrm{Nb}_{2} \mathrm{O}_{5}$ apresentou-se na forma ortorrômbica e o óxido de zinco, na fase cristalina zincite hexagonal.
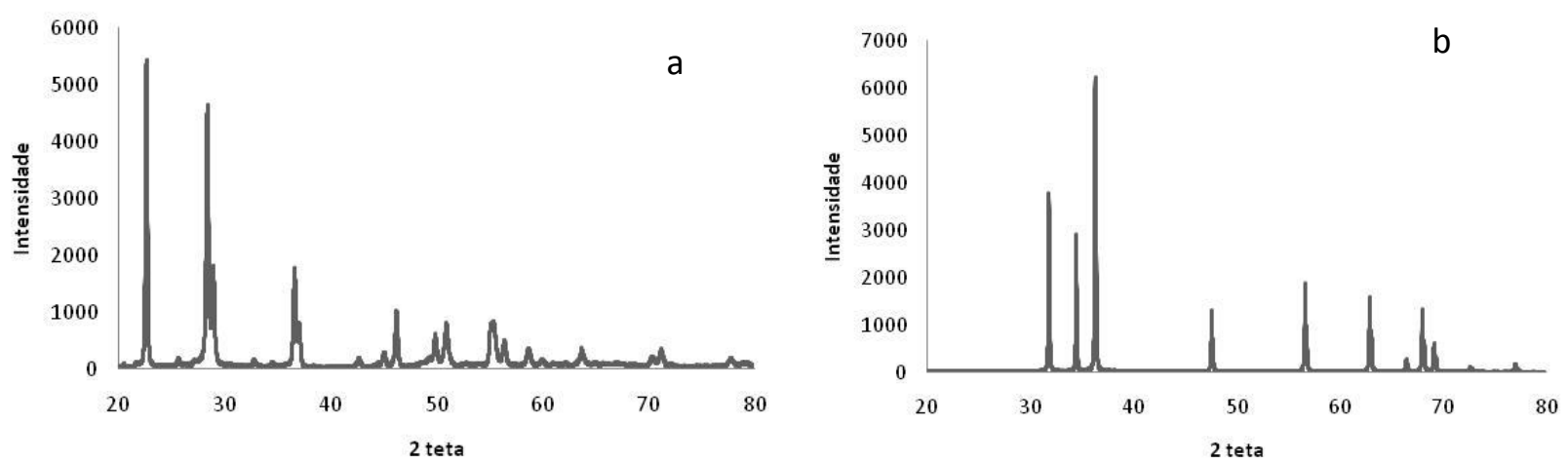

Figura 7 - Difratograma de raio-X do catalisador pentóxido de nióbio(a) e do óxido de zinco(b). 


\subsection{DEGRADAÇÃO FOTOCATALÍTICA DO EFLUENTE DE CELULOSE E PAPEL}

A DQO inicial do efluente era de 180mg/L, com uma concentração de $150 \mathrm{ppm}$ de cloro-ligninae com pH de 8,25. No efluente de indústrias de celulose e papel são encontrados compostos derivados da lignina que dão a forte coloração do mesmo e sua redução implica na redução da coloração do mesmo.

Para a análise da eficiência da fotodegradação do efluente foram feitas análises de DQO e concentração de compostos de cloro-lignina. Os resultados da degradação de compostos cloro-lignina e de DQO são apresentados nas figuras 8 e 9, respectivamente.

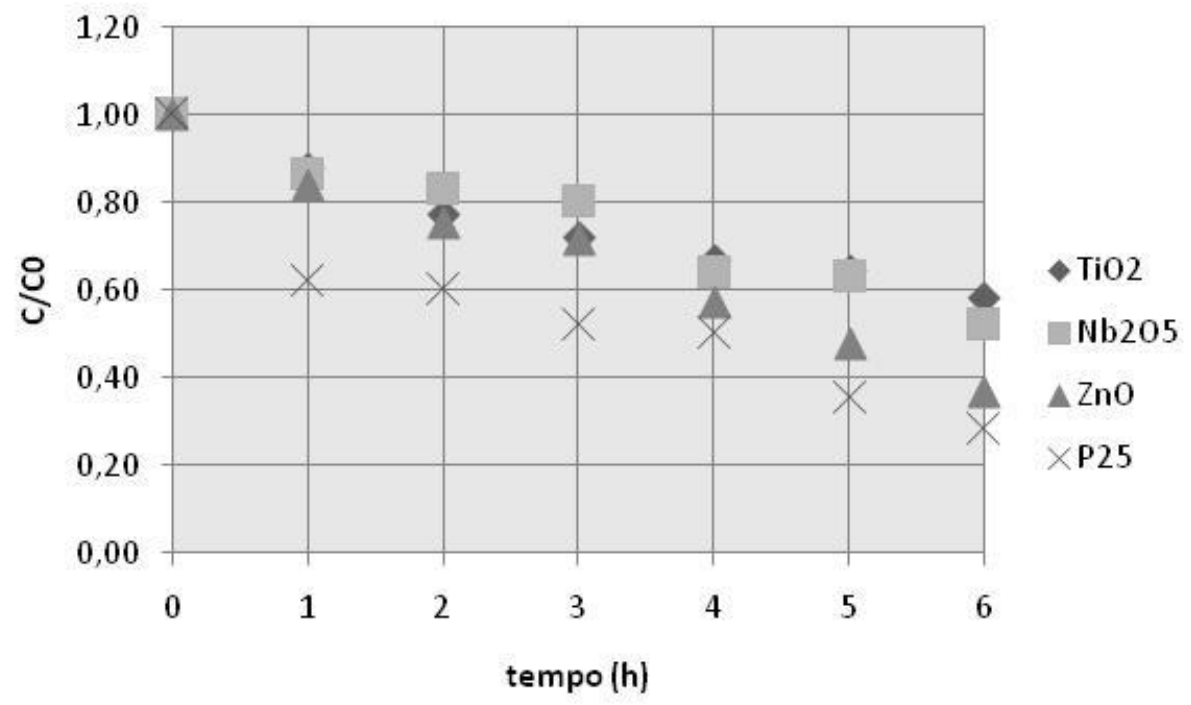

Figura 8 - Redução dos compostos de cloro-lignina do efluente de celulose e papel.

$\mathrm{Na}$ figura 8 observa-se que o catalisador que mais se aproximou da atividade do P25foi o óxido de zinco.Ele teve uma eficiência de redução dos compostos de lignina de $63 \%$.Seu desempenho melhor em relação aos demais catalisadores deve-se à sua melhor dispersão no efluente, observadadurante os testes. A redução de DQO (figura 9) seguiu o mesmo comportamento da redução de compostos cloro-lignina. 


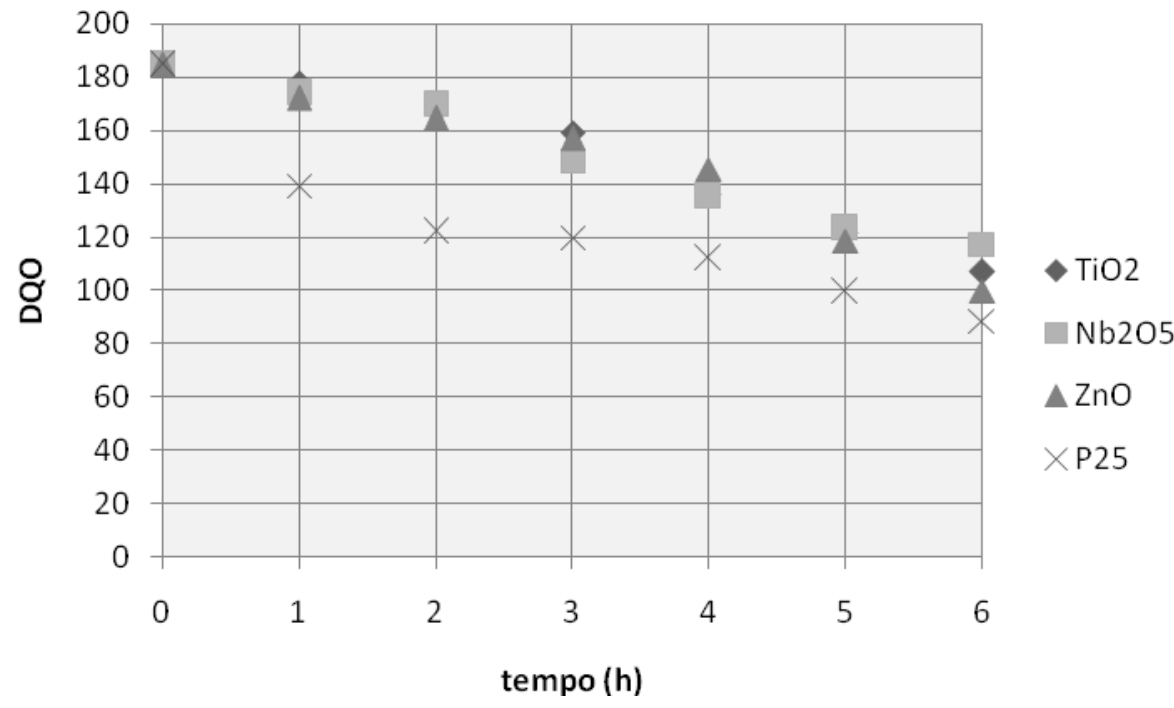

Figura 9 - Redução da DQO do efluente de celulose e papel.

A Figura 10 mostra a porcentagem final de redução de compostos de cloro-lignina e DQO do efluente com os catalisadores utilizados nos testes.

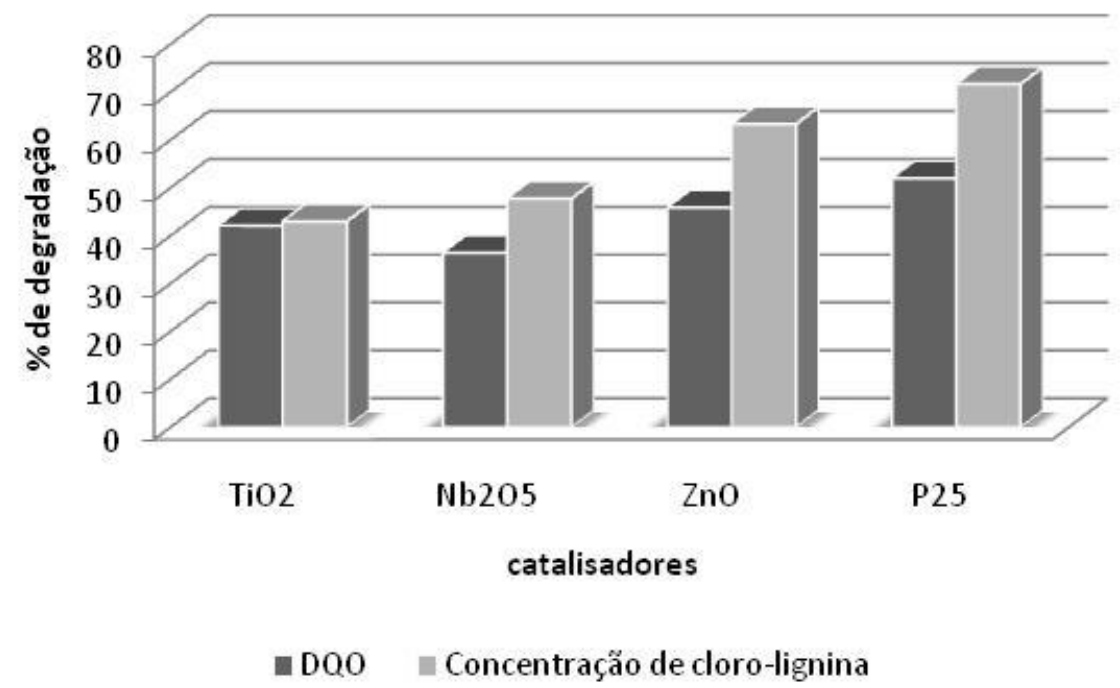

Figura 10 - Redução dos compostos de cloro-lignina do efluente de celulose e papel.

Observando a figura 10 tem-se que o catalisador que apresenta maior atividade catalitica é o óxido de zinco, com uma redução de cloro-lignina e DQO de63 e 46\%, respectivamente, estando próximo do P25 (72 e 52\%).

$\mathrm{Na}$ figura 11 é apresentado o espectro de absorção do efluente antes e após o 
tratamento fotocatalítico com o catalisador $\mathrm{ZnO}$. Observa-se uma redução total da área do espectro de mais de $40 \%$.

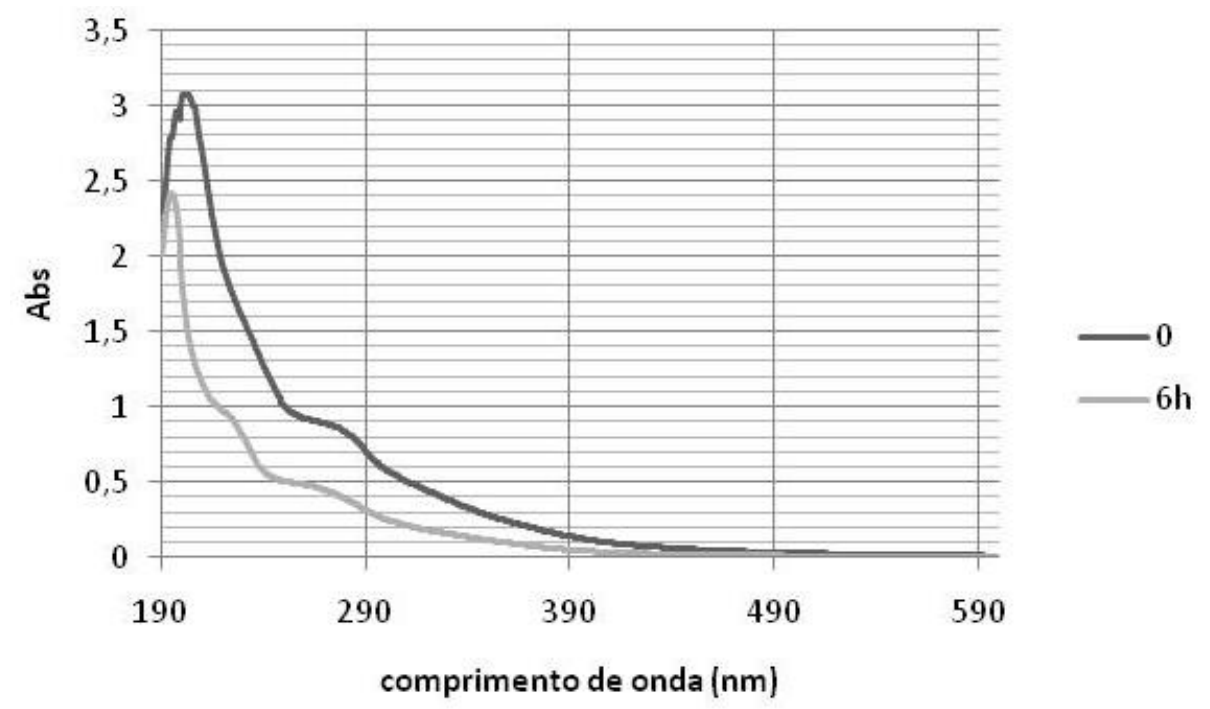

Figura 11 - Redução dos compostos de cloro-lignina do efluente de celulose e papel.

\section{CONCLUSÕES}

Nas análises de difratometria de raio-x verificou-se a fase cristalina dos três óxidos, o $\mathrm{TiO}_{2}$ Kronos fase anatase, o óxido de zinco zincite-hexagonal e o pentóxido de nióbio ortorrômbica. Na caracterização da área superficial total, verificou-se que o catalisador que apresentou maior área superficial foi o pentóxido de nióbio, seguido pelo dióxido de titânio e óxido de zinco.

O catalisador que apresentou uma maior atividade tanto para redução de clorolignina quanto para redução de DQI comparado com o P-25 foi o óxido de zinco, seguido pelo dióxido de titânio Kronos e o pentóxido de nióbio.

\section{REFERÊNCIAS}

ALI,M., SREEKRISHNAN, T.R.,,"Aquatic toxicity from pulp and paper mill effluents: a review”, Advances in Environmental Research, v. 5, pp 175-196, 2001.

ANDRADE, A. S., "Qualidade da madeira, celulose e papel em Pinus taeda L.: Influência da idade e classe de produtividade", Dissertação de mestrado, UFPR, 2006.

CARDOSO, G., "Fabricação de Celulose”.Vol. 1,Ed: Senai. Curitiba - PR. 2006. 
CATALKAYA,E.C., KARGI, F., "Advanced oxidation treatment of pulp mill effluent for TOC and toxicity removals", Journal of Environmental Management, v 87,pp 396-404, 2008.

IPT- Instituto de Pesquisas Tecnológicas do estado de São Paulo, Escola Teobaldo De Nigris. São Paulo, SP, 1988.

KO, C.H., HSIEH, P.H., CHANG, M.W., CHERN, J.M., CHIANG, S.M., TZENG, C.J., "Kinetcs of pulp Mill effluent treatment by ozone-basead process", Jounal of Hazardous Materials, v.168, pp. 875-881, 2009.

LASA, H., SERRANO, B., SALAICES, M., "Photocatalytic Reaction Engineering", 1ํed., Springer Science-Business Media, New York,2005.

PERALTA-ZAMORA, P. ESPÓSITO, E. REYES, J. DURAN, N., "Remediação de Efluentes Derivados da Indústria de Papel e Celulose. Tratamento Biológico e Fotocatalítico" Química Nova. v.20 .pp186-190, 1997.

POKHREL, D.,VIRARAGHAVAN,T.,"Treatment of pulp and paper Mill wastewater-a review", Science oft he Total Environment, 333 , pp37- 58, 2004.

SENAI - CETCEP - apostila de treinamento em tratamento de efluentes, - Centro de Tecnologia em Celulose e Papel. Telêmaco Borba, PR,1995.

BRACELPA: disponível em www.bracelpa.com.br. Acesso em 10 fevereiro de 2012 